\title{
«Di, pues, mi mente a conocer la sabiduría y a en- tender la locura y los desvaríos» (Qohelet 1, 17)
}

\author{
FERNANDO DOMÍNGUEZ REBOIRAS \\ fernando.dominguez@theol.uni-freibrug.de \\ Universidad de Freiburg
}

Tanto la labor docente de Albert Hauf como sus escritos manifiestan una atención particular a las formas y al dinamismo de la racionalidad, a la relación entre la filosofía, las instituciones y los contextos de transmisión del saber. Gracias a un conocimiento poco común de la tradición latina y vernácula sabe delimitar magistralmente la función clarificadora y decisiva de las fuentes para la interpretación de los textos. Convencido de la importancia del proceso histórico y especulativo, Hauf se ha apuntado a una interpretación plural del Medioevo, descubriendo la intrincada red de las diversas corrientes filosóficas, científicas y culturales. Con una pluma ágil y la palabra exacta y concisa sabe atar los nudos que fijan y dan consistencia a tantos hilos que, en una mirada distraída y superficial parecen laberínticos, pero que de hecho van trazando todos los itinerarios posibles para comprender la fascinante y profunda visión medieval de Dios, del hombre y del mundo.

Hauf está en las antípodas de ese vicio, que yo diría franco-español, de la superficialidad brillante y entrometida. Hauf dispone de una actitud científica y virtud teutónica muy valorada y buscada en Centroeuropa pero casi intraducible y poco usada en el vocabulario científico hispano francés: "die Gründlichkeit", literalmente, acribia intelectual, profundización o profundidad que viene mejor definida por una serie de sinónimos como son solidez, minuciosidad, esmero, cuidado, detenimiento, escrupulosidad, exhaustividad, exactitud, hondura y radicalidad. Este concepto abstracto tiene como base el adjetivo "gründlich", es decir, sólido, profundo, hondo, fundamentado, documentado, esmerado, sistemático, y metódico que apuntan a la calidad del esfuerzo que debe implicar toda actividad científica. No quiero terminar este excurso terminológico sin apuntar que detrás de "gründlich" y "Gründlichkeit" está el hermoso, denso y simple término germánico "Grund" que no sólo significa la tierra, el fondo (del mar), el suelo, el terreno firme, la base y el fundamento, sino también el porqué, la razón de una cosa, el motivo y su última causa.

En las primeras lecciones que Johann Gottlieb Fichte en 1794 imparte en la Universidad de Jena y que versaban sobre el destino del sabio y su participación activa dentro de la comunidad a la que pertenece, diserta, como de paso, sobre la hondura y precisión del lenguaje. Este tema preocupa a Fichte y prueba de 
ello es que volverá a tratarlo en diversas ocasiones a lo largo de su vida. Las ideas de esas lecturas que expone ese mismo año en un libro titulado «Algunas lecciones sobre el destino del sabio» sirven como punto de partida para escribir dos artículos que envía a una nueva revista que Friedrich Schiller dirigía. El primero de esos artículos, titulado «Sobre la estimulación y la elevación del interés puro por la verdad» fue publicado en el primer número, pero sorprendentemente el poeta Schiller rechaza un segundo artículo titulado «Sobre la diferencia del espíritu y la letra en la filosofía» porque el estilo empleado en la exposición era, según Schiller, demasiado «seco, pesado y confuso» y no se correspondía, por tanto, con el tono que pedía para su revista. Fichte apunta que él se exige aquella profundidad (Gründlichkeit) lo cual implica «siguiendo mi mejor saber y conciencia» que se ha obligado, se ve ligado, al fondo (Grund) de todo lo que explica. Y, aunque reconoce que podría realizarse por conducto más simple, dice irónicamente que puede exigirle a cualquiera que no intente entender de golpe sino que luche por recorrer lentamente el arduo camino del conocimiento, descansando de cuando en cuando, contemplando el panorama, pues con un poco de paciencia podría llegar a la meta de la comprensión, sin pedirle al expositor un sacrificio de solidez y escrupulosidad en aras de un raciocinio simplista. En resumidas cuentas, lo que primero exige Fichte del sabio es solidez y profundidad, pero, a la vez, exige del oyente aprendiz un esfuerzo de comprensión y la debida preparación negándole al maestro, sobre todo, un sacrificio de rigidez intelectual para adaptarse al ignorante que no quiere esforzarse intelectualmente. Un equilibrio que en la práctica docente se hace tanto más difícil cuanto menos «gründliches Wissen» (conocimientos básicos) puede uno suponer en sus oyentes.

Sin haber sido oyente de Albert Hauf, creo que él es maestro en ese difícil equilibrio y domina con una inusual perfección el arte de ir al fondo de las cosas, que Fichte describe como un «no tener que dar por supuesto todo lo que una inmediata respuesta a una pregunta presupone». Por eso me atrevo yo a aplicarle a Hauf aquel extraño panegírico que el poeta Joseph ben Sassón, residente en Frómista, dedica a su vecino, el poeta rabino Sem Tob ben Yitzhak Ardutiel conocido también como Santob de Carrión:

Eminente caballero que camina por el sendero de la sabiduría... cuyos libros encantan y su decir es hermoso... y con su sabiduría anonada a los sabios que, comparados con él, los demás parecen vacas... es compositor que con su saber destruye rocas.

Pero, aprovechando que citamos a Sem Tob, me paro a considerar algunas sabias advertencias de este rabino, conocido sobre todo como autor de "Proverbios morales", largo poema en español escrito entre 1355 y 1360. Nos dice el buen rabino una verdad como un templo: «... por rregla derecha / El mundo non se guía». Cosa que Ramon Llull también admitía diciendo a menudo que «... mundus est in perverso statu».

Sem Tob sabe bien cómo aquella sabiduría, que, según Góngora, «pretende vender la Universidad», «comprar no se podría / Con cuanto el mundo val». Y así, aunque no olvida la advertencia del sabio Qohelet $(12,12)$ que «el componer 
libros es cosa sin fin, y el excesivo estudio es martirio de la carne», se explaya Sem Tob en el prólogo de «Proverbios morales» interpretando otra frase del mismo Qohelet $(1,18)$ :

E commo quiera que dize Salamon - e dize verdat - en el Libro de los Prouerbios: "Quien acreçienta çiençia acreçienta dolor". Pero entyendo que esto que el llama dolor, que es trabajo del coraçon e del entendimiento. E asi no lo deuemos tener el tal dolor por malo, ca el non lo dixo mal dolor... Ca la çiençia es causa al entendido ponele en folgura corporal e espiritual.

Y Sem Tob, que se esfuerza en interpretar ese dolor como dulce destino del sabio, prosigue:

E avn digo que Salamon, antes e después que escriuio e dixo en los dichos Prouerbios "El que acreçienta çiençia, acresçienta dolor", el acreçento çiençia... Asy que entyende que non lo dixo por mal dolor, cas y lo sintiera por dolor, non se trabajara de acresçentar çiençia. Pero este dolor es asemejado al trabajo de bien fazer: que trabaja omne en yr luengo camino por alcançar complimiento de su deseo, e es aquel trabajo, folgura, gloria e non dolor, avn que pasa por él.

E asi que dixo "acreçienta dolor", por que quien muncho lee, muncho trabaja; e mientra mas acresçienta el estudyo, mas acresçienta trabajo... El fruto que el entendido saca del tal trabajo, o dolor, es de tamaña gloria, que el trabajo e dolor con que se alanço es ninguno, e cosa oluidada e non sentida... Ca dolor ay que omne desea a las vezes, que con el avrie grant folgura, e non syn el: asi que es munchas vezes deseado dolor... asi que es dolor nesçesario, o provechoso.

Para terminar exige Sem Tob del sabio comunicar su sabiduría, retratando así a Albert Hauf:

E por eso non deue çesar de fablar çiençia el que sabe, por cuyta de sofrir trabajos, o dolor. Mayor mente que es notorio que viene por devyna influyda de Dios en el omne que la. Asi que non la da Dios para que la calle, nin para el ynfluydo solo, saluo para fazer bien... Asi que el Señor da sabiduría a vno par enseñar a munchos... Asi que deuemos creer que es bien aprender de quien aprende e entender del que entyende... Asi que non es dolor doloroso, mas es dolor provechoso.

Pero no quiero terminar sin dejar claro que esa frase bíblica, explicada por Sem Tob, es citada a menudo en autores medievales y renacentistas en otro sentido. Sobre todo aquellos perseguidos por su ciencia ven expresado en este texto el dolor que se sufre en la lucha contra la ignorancia. En ella quieren ver cómo Salomón ya advierte al sabio que todo el que acrecienta ciencia acrecienta también el dolor que le infligen los ignorantes y los vagos envidiosos. No sólo supongo, creo cierto que Albert Hauf, como sabio, sufrió el dulce dolor de aprender, pero también, con estoica disciplina y sano humor, aguantó y aguanta los dardos y palos de tanto ignorante que se cree sabio. Un destino que otros com- 
parten con él como fruto natural de la vida del sabio. Por eso Sem Tob dice también, y hago mía su advertencia, que la amistad y hermandad hacen ese sufrimiento más llevadero y que nunca se siente el sabio en soledad.

Non a mejor rryqueza

Que buena ermandat

Nin tan mala pobreza

Como la soledat. 